\title{
Terapia Nutricional Enteral Domiciliar em tempos de isolamento social devido à pandemia de COVID-19
}

\author{
Home Enteral Nutrition in times of social isolation due to the COVID-19 pandemic
}

DOI: $10.37111 /$ braspenj.AE202035301

Emilaine Ferreira dos Santos ${ }^{1}$

Estela Iraci Rabito ${ }^{2}$

Caryna Eurich Mazur ${ }^{3}$

Rubia Daniela Thieme ${ }^{4}$

Maria Eliana Madalozzo Schieferdecker

\section{Unitermos:}

Serviços de Assistência Domiciliar. Assistência Domiciliar. Infecções por Coronavirus. Nutrição enteral. Pandemias.

\section{Keywords:}

Home Care Services. Home Nursing. Coronavirus Infections. Enteral nutrition. Pandemics.

\section{Endereço para correspondência:}

Maria Eliana Madalozzo Schieferdecker

Programa de Pós-Graduação em Alimentação e Nutrição. Universidade Federal do Paraná

Avenida Prefeito Lothário Meissner, 632 - Jardim Botânico - Curitiba, PR, Brasil - CEP 80210-170

E-mail:meliana@ufpr.br

\section{Submissão}

25 de maio de 2020

\section{Aceito para publicação}

1 de setembro de 2020

\section{RESUMO}

A terapia nutricional enteral domiciliar (TNED) proporciona o cuidado à necessidade especial de alimentação no domicílio. Embora a maioria dos pacientes em TNED esteja clinicamente estável, faz-se necessário o apoio de profissionais da saúde e o monitoramento e a avaliação para manutenção ou evolução da terapia. Entretanto, a atual situação de pandemia de COVID-19 e a inexistência de tratamento específico para a infecção pelo coronavírus levaram a alterações na rotina de trabalho dos serviços de saúde. A recomendação de distanciamento social para conter o avanço da COVID-19 interfere no serviço de atendimento domiciliar. Assim, para que se proporcione a assistência de maneira efetiva e com segurança ao paciente, familiares e profissionais da saúde, adaptações podem ser realizadas. Portanto, o objetivo deste manuscrito é discutir elementos e recomendações que contribuam para o cuidado em TNED durante a pandemia de COVID-19.

\section{ABSTRACT}

Home enteral nutrition (HEN) provides care for the special need for food at home. Although the majority of patients in HEN is clinically stable, support from health professionals, and monitoring and evaluation for maintenance or evolution of therapy are necessary. However, the current pandemic situation of COVID-19 and the lack of specific treatment for coronavirus infection have led to changes in the health services work routine. The social distance recommendation to contain the progress of COVID-19 interferes with the home care service. Thus, in order to provide assistance effectively and safely to the patient, family members and health professionals, adaptations can be made. Therefore, the objective of this manuscript is to discuss elements and recommendations that contribute to HEN care during the COVID-19 pandemic.

1. Mestranda do Programa de Pós-Graduação em Alimentação e Nutrição, Universidade Federal do Paraná (UFPR), Curitiba, PR, Brasil.

2. Professora Doutora do Departamento de Nutrição e do Programa de Pós-Graduação em Alimentação e Nutrição, Universidade Federal do Paraná (UFPR), Curitiba, PR, Brasil.

3. Professora Doutora do Departamento de Nutrição. Universidade Estadual do Centro-Oeste (UNICENTRO), Guarapuava, PR, Brasil.

4. Doutoranda do Programa de Pós-Graduação em Políticas Públicas, Universidade Federal do Paraná (UFPR), Curitiba, PR, Brasil. 


\section{INTRODUÇÃO}

A terapia nutricional enteral domiciliar (TNED) é indicada quando há restrição de utilização da via oral para alimentação e objetiva manter ou recuperar o estado nutricional do paciente' ${ }^{1}$. Diante da possibilidade de continuidade ao tratamento clínico e nutricional em domicílio, a TNED é a alternativa recomendada a longo prazo ${ }^{1,2}$. As neoplasias, os distúrbios neurológicos, neurodegenerativos, traumas e problemas de má absorção são enfermidades com indicação frequente de TNED².

A indicação de cuidados em domicílio depende da estabilidade clínica do paciente, que orienta qual ponto da rede de atenção à saúde (RAS) prestará assistência mais adequada $^{3}$. A atenção domiciliar (AD) está integrada à RAS e apresenta importante papel na recuperação ou manutenção da saúde do paciente, além de estar associada à melhoria no seu convívio social e familiar e da sua qualidade de vida ${ }^{2,4}$. Porém, algumas situações podem exigir reorganização das rotinas de profissionais da saúde na $A D$, bem como dos cuidadores e da família do paciente em TNED, como é o caso de pandemias.

A pandemia do novo coronavírus é considerada pela Organização Mundial da Saúde (OMS) uma Emergência de Saúde Pública de Importância Internacional (ESPII) ${ }^{5}$. Ao final de 2019, na cidade de Wuhan, localizada na província de Hubei, China, teve início o surto desse novo vírus, que apresentava quadros clínicos de síndrome gripal aguda associada à pneumonia viral, até então de etiologia desconhecida ${ }^{6-8}$. Após a coleta de amostras, foi identificado que o patógeno se tratava de um novo coronavírus denominado SARS-CoV- $2^{7}$. Com isso, a OMS foi notificada e definiu o nome para nova doença: COVID-199. Devido à sua alta transmissibilidade por gotículas ou secreções respiratórias e ao avanço da doença entre os continentes, em março de 2020, a OMS declarou o estado de pandemia ${ }^{10}$.

Diante de uma ESPII, a OMS recomenda várias medidas aos Estados Membros, como: vacinação, quarentena e isolamento social ${ }^{5}$. Porém, atualmente, não se tem medicamento ou vacina específica para prevenir ou tratar a COVID-19. Portanto, recomenda-se o distanciamento social como meio de frear a transmissão e a propagação do vírus e da infecção $0^{11,12}$. Devido à magnitude da pandemia, os governos são responsáveis por garantir a saúde da sua população e são orientados a recomendar estratégias que possibilitem a segurança tanto para o paciente quanto para o profissional $\left.\right|^{5,13}$.

Considerando a recomendação de distanciamento social, espera-se que o domicílio seja o lugar mais seguro, enquanto a ESPII pela pandemia da COVID-19 se mantiver. Porém, em caso de realização de tratamento domiciliar por agravo à saúde diferente da infecção por COVID-19, alguns cuidados adicionais são indicados para evitar a contaminação com o novo coronavírus. Essa situação é vivenciada por pacientes em uso da TNED, que embora, em maioria, clinicamente estáveis, normalmente possuem doenças de base e comorbidades associadas que podem comprometer o prognóstico favorável em caso de infecção pelo novo coronavírus.

Frente à gravidade da atual situação de saúde pública, faz-se necessário rever as ações e práticas de AD. Neste sentido, é preciso reorganizar serviços para que se garanta atendimento de qualidade, eficiente e, principalmente, com segurança ao paciente, cuidadores, familiares e profissionais da saúde. Com isso, o objetivo deste manuscrito é discutir elementos e recomendações que contribuem para o cuidado em TNED durante a pandemia de COVID-19. Para alcançar o objetivo, este manuscrito buscou utilizar materiais e orientações governamentais e de entidades nacionais e internacionais de saúde voltadas ao enfrentamento da ESPII publicados e disponíveis até o momento, no site do Ministério da Saúde Brasileiro e na base de dados LILACS. Ainda, foram considerados os artigos científicos referentes à temática do cuidado nutricional em TNED elaborados e publicados por pesquisadores estrangeiros disponíveis na base de dados PubMed.

Assim, com base nas publicações e no conhecimento preexistente do processo de trabalho e assistência prestada anteriormente à pandemia, as orientações e recomendações foram adaptadas para o público em questão, ou seja, pacientes em uso da TNED no contexto brasileiro. Para apresentação das orientações e recomendações, optouse por dividir o texto em três partes: 1. Monitoramento do paciente em TNED; 2. Recomendações para higienização de superfícies no domicílio; e 3. Orientação aos cuidadores de pacientes em TNED.

\section{MONITORAMENTO DO PACIENTE EM TERAPIA NUTRICIONAL ENTERAL DOMICILIAR}

A telemedicina, atendimento remoto e consultas não presenciais foram autorizados no Brasil por entidades representativas de diferentes profissões da área da saúde e outras instituições em virtude da pandemia do novo coronavírus. A formulação de legislação e normas foi iniciada no fim de março de 2020 e estão disponíveis para toda a população. Desde então, Conselho Federal de Medicina (CFM - Ofício 1756/2020)14, Conselho Federal de Nutricionistas (CFN - Resolução No 646/2020)15, Conselho Federal de Enfermagem (COFEN - RESOLUÇÃO COFEN No $634 / 2020)^{16} \mathrm{e}$ outros Conselhos Federais e o Ministério da Saúde ${ }^{17}$ (Portaria $467 / 2020$ ) recomendaram modificações e ajustes para a atuação dos profissionais da saúde enquanto perdurar a situação de ESPII. 
Portanto, ligações telefônicas ou videochamadas são estratégias que podem ser utilizadas para monitoramento e continuidade do cuidado de saúde. As recomendações gerais para o atendimento domiciliar, com vistas ao monitoramento de pacientes em TNED, estão apresentadas no Quadro 1.

Em casos específicos, quando não há possibilidade de atendimento remoto, recomenda-se que sejam obedecidas todas as normas de segurança, a fim de evitar a exposição dos pacientes em TNED, cuidadores, familiares e profissionais da saúde ao contágio pelo novo coronavírus ${ }^{20}$ (Quadro 2).

Quadro 1 - Recomendações para realização de monitoramento remoto por profissionais de saúde com vistas aos cuidados a pacientes em terapia nutricional enteral domiciliar.

\section{Recomendações gerais para ações de atenção domiciliar realizadas remotamente}

- Fazer o contato via telefone ou outras formas de comunicação à distância;

- Manter registro do contato com o paciente e familiares;

- Orientar quanto às dúvidas e dificuldades em relação à TNED;

- Sempre que possível, aplicar a triagem de risco de desnutrição (MUST e SARC-F);

- Quando o contato por videochamada for realizado, orientar o paciente em TNED ou cuidador para realizar o exame físico visual, inspecionando a reserva muscular, a hidratação e a condição da sonda ou ostomia (incluindo a higienização);

- Avaliar alterações de peso corpóreo do paciente em TNED, mesmo que de forma subjetiva;

- Investigar o tipo da fórmula e quantidade infundida, bem como a tolerância pelo paciente em TNED e a presença de intercorrências gastrointestinais;

- Questionar sobre a presença de sintomas relacionados à alteração da frequência respiratória, febre, sintomas gripais;

- Realizar avaliação referente à hidratação do paciente em TNED;

- Avaliar a necessidade de alteração ou adequação da prescrição dietética e a melhor forma de encaminhá-la ao paciente em TNED ou cuidadores;

- Realizar triagem por telefone de pacientes em TNED, cuidadores e familiares com manifestações clínicas relacionadas à COVID-19;

- Orientar todos os pacientes em TNED e seus familiares sobre prevenção e cuidados gerais, isolamento domiciliar de indivíduos sob suspeita de COVID-19 no grupo familiar, distanciamento social e manifestações clínicas que necessitem de atendimento de urgência;

- Realizar triagem de famílias em vulnerabilidade social e buscar medida protetiva intersetorial por meio da assistência social;

- Promover ação que mantenha a distribuição de medicações, fórmulas nutricionais comerciais e materiais de higiene fornecidos pela rede de serviço de saúde em domicílio.

Adaptado de Matras et al. ${ }^{18} \mathrm{e}$ Krznaric et al. ${ }^{19}$.

TNED = Terapia Nutricional Enteral Domiciliar; COVID-19 = Corona Virus Disease; MUST = Malnutrition Universal Screening Tool - em português Ferramenta Universal para Rastreio da Malnutrição; SARC-F = Strength, Assistance in walking, Rise from a chair, Climb stairs e Falls - em português conhecido como questionário para triagem de sarcopenia.
Quadro 2 - Principais orientações para a prevenção da COVID-19 no atendimento presencial no domicílio.

Orientações de boas práticas para 0 atendimento nutricional presencial para prevenção de COVID-19

- Evitar contato físico, como abraço e aperto de mão;

- Realizar contato remoto (por telefone, por exemplo) antes e questionar sobre o aparecimento de sintomas da COVID-19 no paciente em TNED, cuidadores e familiares;

- Orientar o cuidador ou paciente em TNED para que, antes da visita domiciliar, o ambiente seja arejado e ventilado;

- Orientar a utilização de máscara pelo cuidador, familiares e paciente em TNED;

- Realizar a higienização com álcool a 70\% em equipamentos como balança, fita antropométrica e adipômetro, bem como o equipamento/ ferramentas utilizados durante registro do atendimento, antes e após a utilização;

- Lavar as mãos com água e sabonete líquido, por, no mínimo, 20-30 segundos, quando possível, e finalizar com álcool a 70\%;

- Utilizar equipamentos de proteção individual (EPI), como: máscara, protetores faciais, luvas, jaleco, antes de adentrar ao domicílio;

- Sempre que possível, manter distância de, no mínimo, 2 metros do paciente em TNED, cuidador e familiares;

- Evitar o preenchimento de fichas ou a entrega de papéis; mas, caso seja necessário, sugere-se que estejam plastificados ou envoltos em plástico transparente para correta higienização;

- Fazer o descarte correto dos EPIs utilizados em lixeira apropriada;

- Ficar atento às normas e protocolos atualizados.

Adaptado de Matras et al. ${ }^{18}$; Brasil, Ministério da Saúde ${ }^{21}$

COVID-19 = Corona Virus Disease; EPI = Equipamento de proteção individual; TNED = Terapia nutricional enteral domiciliar.

\section{RECOMENDAÇÕES PARA HIGIENIZAÇÃO DE SUPERFÍCIES NO DOMICÍLIO}

O tempo de permanência do novo coronavírus em várias superfícies já foi identificado, sendo variável de acordo com o material do objeto. $\bigcirc$ respeito às orientações de hábitos de higiene é eficiente no combate ao vírus, desde que seguidos adequadamente ${ }^{12}$. A manipulação das fórmulas enterais para TNED por si só já deve seguir condutas de higiene para garantir a qualidade na oferta. Nabarrete et al. ${ }^{22}$, em publicação recente, apresentaram recomendações a pacientes oncológicos sobre cuidados com a higienização de alimentos e que podem ser seguidas pelos usuários em TNED e familiares (Quadro 3).

Vale, ainda, ressaltar a importância dos cuidados essenciais para manuseio e preparo da nutrição enteral, que devem ser mantidos e reforçados ${ }^{4}$ (Quadro 4). 
Quadro 3 - Principais orientações para higienização de alimentos em domicílio.

\section{Orientações para higienização de alimentos}

- Lavar bem as mãos com água e sabão, por 20-30 segundos, antes de iniciar o manuseio de alimentos;

- Antes de armazenar compras ou itens recebidos por doação ou outro meio, higienizar as embalagens com papel toalha ou pano e álcool a 70\%, logo após chegar no domicílio;

- Realizar o procedimento de higienização de frutas e hortaliças in natura com hipoclorito de sódio (concentração de 100 a 200 ppm por 15 minutos), antes do armazenamento;

- Nutricionista deve reforçar os cuidados no preparo, como: higienização do ambiente, lavagem correta das mãos e armazenamento correto de lixo e descartes.

Adaptado de Nabarrete et al. ${ }^{22}$.

Quadro 4 - Principais orientações para manuseio e preparo de fórmulas para terapia nutricional enteral domiciliar.

\section{Orientações para manuseio e preparo da fórmula no domicílio}

- Armazenar gêneros alimentícios ou fórmulas comerciais em ambiente arejado e com limpeza constante;

- Higienizar corretamente materiais e utensílios utilizados no preparo ou diluição, bem como na administração da nutrição enteral; preferencialmente, utilizar os utensílios exclusivamente para o paciente em TNED;

- Orientar o manipulador a manter o cabelo preso e utilizar touca durante todo o processo, bem como não utilizar anéis ou colares e manter unhas aparadas e limpas;

- Utilizar, sempre que possível, máscara, especialmente em caso de sintomas respiratórios leves ou moderados;

- Ao preparo da nutrição enteral para o dia todo, orientar a realização do fracionamento em recipiente adequado, assim como a conservação da nutrição enteral preparada em refrigerador;

- Reforçar a importância da lavagem das mãos antes e após a administração das fórmulas enterais.

Adaptado de Brasil, Ministério da Saúde ${ }^{4}$.

\section{ORIENTAÇÃO AOS CUIDADORES DE PACIENTES EM TERAPIA NUTRICIONAL ENTERAL DOMICILIAR}

O distanciamento social é a medida mais eficaz no momento para retardar a disseminação da COVID-1911,12. É primordial evitar aglomerações, bem como o contato com pessoas externas ao convívio domiciliar. Para paciente em TNED, é fundamental que esse contato seja restrito, em virtude do risco da infecção. Os cuidadores, tanto familiares quanto os contratados para essa função, devem ser orientados quanto aos cuidados com o paciente em TNED, de higiene na preparação e administração da nutrição enteral. Os cuidadores formais, ou seja, contratados, que não moram no mesmo domicílio do paciente em TNED, devem tomar os cuidados necessários durante seu deslocamento até o local de trabalho, conforme orientam a OMS e o Ministério da Saúde, bem como devem ficar atentos a sintomas da infecção e se afastar do paciente em TNED, em caso da presença dos mesmos.

Ainda, os cuidadores devem receber dos profissionais da saúde orientações sobre o contato com pessoas externas, como visitas de familiares e amigos ao paciente em TNED. Nesse caso, é importante que se tenha restrição de visitas e, se necessária a realização da visita, esses indivíduos devem obedecer a todas as recomendações dos órgãos e entidades de saúde quanto à proteção ao novo coronavírus.

Outra recomendação para o cuidador ou responsável é a realização do planejamento de saídas do domicílio para serviços essenciais, como farmácia e mercado. Ao fazê-la, devem ser adotadas todas as recomendações preconizadas, como uso de máscara, distanciamento e higienização das mãos ${ }^{23}$.

Conforme relatado por Matras et al. ${ }^{18}$, a qualificação quanto à pandemia e aos procedimentos padronizados da equipe de profissionais da saúde e do cuidador são importantes para garantir a adequada assistência ao paciente. Em caso de sintomas respiratórios (febre, tosse, falta de ar, dores musculares, etc) manifestados pelo cuidador, paciente ou qualquer membro da família, é fundamental a procura por atendimento médico.

\section{CONCLUSÃO}

Apesar do período de pandemia, a assistência prestada ao paciente em TNED deve transcorrer com qualidade, eficiência e com a garantia de todos os esforços necessários para a boa evolução clínica. Embora sejam escassas, neste momento, as referências específicas para TNED, ressalta-se a importância da reorganização dos serviços de AD baseada nas recomendações e protocolos de órgãos e entidades da saúde, os quais estão disponíveis neste período de ESPII.

\section{REFERÊNCIAS}

1. Gramlich L, Hurt RT, Jin J, Mundi MS. Home enteral nutrition: towards a standard of care. Nutrients. 2018;10(8):1020.

2. Bischoff SC, Austin P, Boeykens K, Chourdakis M, Cuerda C, Jonkers-Schuitema C, et al. ESPEN guideline on home enteral nutrition. Clin Nutr. 2019;39(1):5-22.

3. Brasil. Ministério da Saúde. Portaria de consolidação no 5 , de 28 de setembro de 2017. Consolidação das normas sobre as ações e os serviços de saúde do Sistema Único de Saúde. Diário Oficial da União, n. Suplemento; 2017.

4. Brasil. Ministério da Saúde. Secretaria de Atenção à Saúde. Departamento de Atenção Básica. Cadernos de Atenção Domiciliar, vol.3. Cuidados em terapia nutricional. Brasília: Ministério da Saúde; 2015.

5. World Health Organization (WHO). International health regulations. $3^{\text {rd }}$ ed. Geneva: WHO; 2016.

6. Sheng WH, Ko WC, Huang YC, Hsueh PR. SARS-CoV-2 e COVID-19. J Microbiol Immunol Infect. 2020;53(3):363-4. 
7. Zhu N, Zhang D, Wang W, Li X, Yang B, Song J, et al; China Novel Coronavirus Investigating and Research Team. A novel coronavirus from patients with pneumonia in China, 2019. N Engl J Med. 2020;382(8):727-33.

8. Bogoch II, Watts A, Thomas-Bachli A, Huber C, Kraemer MUG, Khan K. Pneumonia of unknown aetiology in Wuhan, China: potential for international spread via commercial air travel. J Travel Med. 2020;27(2):taaa008.

9. Velavan TP, Meyer CG. The COVID-19 epidemic. Trop Med Int Health. 2020;25(3):278-80.

10. World Health Organization. Coronavirus disease (COVID2019): situation report 72 [Internet]. Geneva: World Health Organization; 2020 [cited 2020 Aug 20]. Available from: https:// www.who.int/docs/default-source/coronaviruse/situationreports/20200401-sitrep-72-covid-19.pdf?sfvrsn=3dd8971b_2

11. Rothan HA, Byrareddy SN. The epidemiology and pathogenesis of coronavirus disease (COVID-19) outbreak. J Autoimmun. 2020;109:102433.

12. Gilbert GL. SARS, MERS and COVID-19-new threats; old lessons. Int J Epidemiol. 2020;49(3):726-8.

13. Lai X, Wang M, Qin C, Tan L, Ran L, Chen D, et al. Coronavirus disease 2019 (COVID-2019) infection among health care workers and implications for prevention measures in a tertiary hospital in Wuhan, China. JAMA New Open. 2020;3(5):e209666.

14. Conselho Federal de Medicina. Define e disciplina a telemedicina como forma de prestação de serviços médicos mediados por tecnologias. Resolução CFM nº 2.228/2019[Internet]; 2020.

15. Conselho Federal de Nutricionistas. Suspende até o dia 31 de agosto de 2020 o disposto no artigo 36 da Resolução CFN n ${ }^{\circ}$ 599, de 25 de fevereiro de 2018, que aprova o Código de Ética e de Conduta dos Nutricionistas. Resolução CFN n ${ }^{\circ}$ 646, de 18 de março de 2020.

16. Conselho Federal de Enfermagem. Autoriza e normatiza, "ad referendum" do Plenário do Cofen, a teleconsulta de enfermagem como forma de combate à pandemia provocada pelo novo coronavírus (Sars-Cov-2), mediante consultas, esclarecimentos, encaminhamentos e orientações com uso de meios tecnológicos, e dá outras providências. Resolução COFEN Nº 0634, de 26 de março de 2020.

17. Brasil. Ministério da Saúde. Nota Técnica GVIMS/GGTES/ ANVISA N ${ }^{\circ}$ 04/2020. Orientações para serviços de saúde: medidas de prevenção e controle que devem ser adotadas durante a assistência aos casos suspeitos ou confirmados de infecção pelo novo coronavírus (SARS-CoV-2). Brasília: Ministério da Saúde; 2020.

18. Matras P, Klek S, Folwarski M, Zmarzly A, Bartoszewska L, Cebulski W, et al. Home medical nutrition during SARS-CoV-2 pandemic: a position paper. Clin Nutr ESPEN. 2020;38:196-200.

19. Krznarić Ž, Bender DV, Laviano A, Cuerda C, Landi F, Monteiro $\mathrm{R}$, et al. A simple remote nutritional screening tool and practical guidance for nutritional care in primary practice the COVID-19 pandemic. Clin Nutr. 2020;39(7):1983-7.

20. Conselho Federal de Nutricionistas. Recomendações do CFN: boas práticas para a atuação do nutricionista e do técnico em nutrição e dietética durante a pandemia do novo coronavírus (COVID-19) [Internet]. $3^{\mathrm{a}}$ ed. rev. ampl. Brasília: Conselho Federal de Nutricionistas; 2020. [cited 2020 Aug 28]. Available from: https://www.cfn.org.br/wp-content/uploads/2020/03/ nota_coronavirus_3-1.pdf

21. Brasil. Ministério da Saúde. Protocolo de manejo clínico do coronavírus (COVID-19) na atenção primária à saúde. Brasília: Ministério da Saúde; 2020.

22. Nabarrete JM, D'Almeida CA, Castro MG, Toledo DO. Recomendações nutricionais para o paciente com câncer durante a pandemia do coronavírus (COVID-19). BRASPEN J. 2020;35(1):9-12.

23. World Health Organization. Advice on the use of masks the community, during homecare and in health care settings in the context of the novel coronavirus (2019-nCoV). Outbreak Interim Guidance. [cited 2020 Aug 28]. Available from: https://www. who.int/publications-detail/ Published 2020.

Local de realização do estudo: Universidade Federal do Paraná (UFPR), Curitiba, PR, Brasil.

Conflito de interesse: Os autores declaram não haver. 